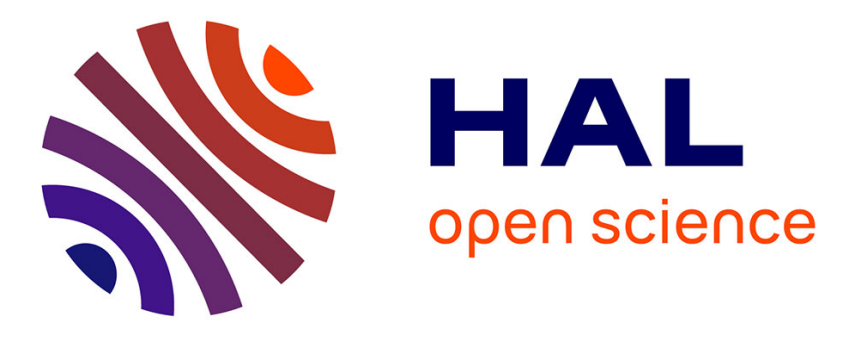

\title{
Effect of carrier oil on the properties of sodium caseinate stabilized $\mathrm{O} / \mathrm{W}$ nanoemulsions containing Trans-cinnamaldehyde
}

Wei Liao, Adem Gharsallaoui, Emilie Dumas, Sami Ghnimi, Abdelhamid Elaissari

\section{To cite this version:}

Wei Liao, Adem Gharsallaoui, Emilie Dumas, Sami Ghnimi, Abdelhamid Elaissari. Effect of carrier oil on the properties of sodium caseinate stabilized $\mathrm{O} / \mathrm{W}$ nanoemulsions containing Trans-cinnamaldehyde. LWT - Food Science and Technology, 2021, 146, pp.111655. 10.1016/j.lwt.2021.111655 . hal-03221648

\section{HAL Id: hal-03221648 \\ https://hal.science/hal-03221648}

Submitted on 29 Oct 2021

HAL is a multi-disciplinary open access archive for the deposit and dissemination of scientific research documents, whether they are published or not. The documents may come from teaching and research institutions in France or abroad, or from public or private research centers.
L'archive ouverte pluridisciplinaire HAL, est destinée au dépôt et à la diffusion de documents scientifiques de niveau recherche, publiés ou non, émanant des établissements d'enseignement et de recherche français ou étrangers, des laboratoires publics ou privés. 

Novembre 1918, 69622 Villeurbanne, France

7

15 *Corresponding author:

16 Dr. Adem Gharsallaoui

17 adem.gharsallaoui@univ-lyon1.fr

$18 \quad$ Phone $(+33) 474455252$
FRANCE 


\section{Abstract}

In this study, the impact of different contents of medium-chain triacylglycerols (MCT) and

21 long-chain triacylglycerols (LCT) as carrier oils mixed with trans-cinnamaldehyde (TCA) on the 22 properties of sodium caseinate-stabilized nanoemulsions was investigated. The obtained results

23 showed that the use of a carrier oil improves significantly the TCA emulsion stability, which can

24 be attributed to a reduction of TCA solubility in the aqueous phase followed by a decrease of 25 Ostwald ripening. This stability improvement was observed at different $\mathrm{pHs}(3,7$ and 11), salt 26 concentrations $(0-300 \mathrm{mmol} / \mathrm{L})$, and temperature $\left(4,25,60\right.$, and $\left.80{ }^{\circ} \mathrm{C}\right)$. However, the carrier oil

27 type (MCT or LCT) did not show any significant effect on the nanoemulsions properties whatever 28 the environmental conditions. Antibacterial testing revealed that the addition of carrier oil 29 increased the antibacterial activity of TCA against Escherichia coli and Listeria innocua. These 30 results are useful for expanding the application of TCA as food preservative in food industry.

32 Keyword: Nanoemulsion; Sodium caseinate; trans-Cinnamaldehyde; Carrier oil; Antibacterial 33 activity. 


\section{Introduction}

It is well established that food preservation is a great challenge and a significant concern in the food industries and the most serious concern of food spoilage remains that of foodborne pathogens. To solve these problems, synthetic preservatives and chemical antimicrobial agents are extensively applied in preventing microbial deterioration of food products and increasing their shelf lives. However, given the growing public concern associated with the use of chemical preservatives, there is an urgent need to be substituted by natural antimicrobial agents. Several natural antimicrobial agents, such as essential oils (EOs), lysozyme, bacteriocins, chitosan and phenolic compounds were applied for food preservation in different ways (Saeed et al., 2019).

Trans-Cinnamaldehyde (3-phenyl-2-propenal, TCA) is the major constituent of the essential volatile oil extracted from cinnamon, a traditional flavoring agent. TCA is an aromatic perfumes (Shreaz et al., 2016). Over the years, numerous studies have indicated that TCA possessed brilliant antibacterial activity with broad-spectrum against bacteria, yeasts, and molds, such as Salmonella spp., Campylobacter jejuni, Cronobacter sakazakii, Listeria innocua (Doyle

\& Stephens, 2019a), Laetiporus sulphureus, Clostridium difficile (Mooyottu et al., 2014) and Saccharomyces cerevisiae (Mochida et al., 1988). Thus, TCA may act as a good alternative to synthetic chemical preservatives due to its potential antibacterial activity and safety. Nonetheless,

54 TCA, in its free form, has a low water-solubility and it is difficult to introduce this EO into aqueous-

55 based foods. Moreover, TCA is a volatile compound easily denatured at room temperature, which 56 limits its use in food processing (Jo et al., 2015). 
Recently, encapsulation techniques, such as emulsion-based encapsulation process, are

58 generally used as delivery systems for EOs. Particularly, oil-in-water emulsion systems are

59 particularly suitable for encapsulating these lipophilic bioactive components and the average size

60 can play an important role in the efficiency of these systems. Indeed, nanoemulsions may have

61 better physical and chemical stability compared to conventional emulsions for encapsulating

62 bioactive components because of their nanometric size $(20-500 \mathrm{~nm})$ and high surface area

63 (Polychniatou \& Tzia, 2018). Thus, nanoemulsion-based systems can provide many advantages,

64 such as protecting hydrophobic bioactive agents from chemical degradation, limiting their volatility,

65 increasing their biological activity, and minimizing the impact on the organoleptic characteristics

66 of food products (Donsì et al., 2011). In addition, nanoemulsions are more kinetically stable than

67 conventional emulsions but they are more susceptible to Ostwald ripening due to their small droplet

68 size (McClements \& Rao, 2011). As a result, they tend to undergo physical changes during storage,

69 which may lead to undesirable alterations in appearance, texture, and shelf life of food products.

70 Chen et al. (2018) showed that nanoemulsions containing pure cinnamaldehyde encapsulated by

71 whey proteins is not physically stable due to a significant change in their size. This phenomenon

72 might be attributed to the high water solubility of cinnamaldehyde, which causes droplet growth

73 through Ostwald ripening (Riquelme et al., 2019). Accordingly, it is necessary to properly design

74 nanoemulsion-based delivery systems to ensure that they have good physical stability in different

75 conditions. Walker et al. (2017) indicated that carrier oil can be incorporated into the oily phase

76 of nanoemulsions to improve its physical and oxidative stability. In another study reported by

77 Donsì et al. (2012), the authors added sunflower oil to the lipid phase to overcome Ostwald ripening

78 of carvacrol, d-limonene and trans-cinnamaldehyde nanoemulsions prepared by high pressure

79 homogenization. In the same context, McClements (2012) developed beverage emulsions by 
addition of poorly water soluble oils to inhibit Ostwald Ripening. Walker et al. confirmed (2017)

81 that the key to enhance the stability of nanoemulsions depends on the physical properties of the

82 carrier oil, such as viscosity, density, and water-solubility. For instance, it has been shown that: (i)

83 combining poor water-solubility carrier oils with hydrophobic bioactive phase, has been shown to

84 enhance physical stability of nanoemulsions by inhibiting Ostwald ripening (Julian McClements et

85 al., 2012); (ii) combining low-viscosity carrier oils with hydrophobic bioactive phase can be used

86 to reduce the size of nanoemulsion droplets during high-pressure homogenization (Qian \&

87 McClements, 2011); and (iii) combining carrier oils containing natural antioxidant or antibacterial

88 agents with hydrophobic bioactive phase may endow different bioactive properties (Li et al., 2015;

89 Meroni \& Raikos, 2018).

In order to study, the effect of the chain length of oil carrier, two different triacylglycerols were used in this work to improve the properties of TCA oil-in-water nanoemulsions: a medium chain triacylglycerol (MCT) and a long chain triacylglycerol (LCT). The used MCT is typically rich

93 in saturated medium chain fatty acids $\left(\mathrm{C}_{8: 0}\right.$ and $\left.\mathrm{C}_{10: 0}\right)$ and the LCT is derived from the linoleic acid 94 and oleic acid $\left(\mathrm{C}_{18: 0}\right)$. Both carrier oils show low water solubility compared with TCA, and they 95 can be used to prepare nanoemulsions to inhibit Ostwald ripening. In addition, the consequences 96 of these structural differences on the stability of emulsions, and consequently on their functional 97 properties, deserve to be evaluated. Sodium caseinate was selected as emulsifier in this study 98 because it is one of the most widely used proteins and has considerable emulsification, gelling and 99 nutritional properties (Choi et al., 2009). The effects of parameters such as $\mathrm{pH}$, ionic strength, and 100 temperature on the stability as well as on the antibacterial activity of the nanoemulsions were also 101 compared. The information generated by this study could be valuable for improving the functional 102 performance and physical stability of food emulsion systems containing essential oil. 


\section{Materials and methods}

104

105

106

107

108

109

110

111

112

113

\subsection{Materials}

Sodium caseinate powder was purchased from Fisher Scientific (United Kingdom). Protein content in sodium caseinate determined by the Kjeldahl method was $93.20 \%$ (nitrogen conversion factor $\mathrm{N}=6.38$ ). A medium chain triacylglycerol oil (MCT) was purchased from Gattefossé (SaintPriest, France). A long chain triacylglycerol oil (sunflower oil, LCT) was purchased from a local Market. Trans-cinnamaldehyde (CA, 99\%) was purchased from Sigma-Aldrich (St Quentin Fallavier, France). The summary of some physicochemical properties of three different oils are shown in Table 1. Analytical grade sodium chloride, imidazole, acetic acid, sodium hydroxide, and hydrochloric acid, were purchased from Sigma-Aldrich Chimie (St Quentin Fallavier, France). All the solutions were prepared in deionized water.

\subsection{Preparation of nanoemulsions}

A pre-emulsion was formulated by dispersing the lipid phase $(10 \mathrm{~g} / 100 \mathrm{~g})$ in the continuous phase, which consisted of $(1 \mathrm{~g} / 100 \mathrm{~g})$ sodium caseinate and $(89 \mathrm{~g} / 100 \mathrm{~g})$ buffer solution $(5 \mathrm{mmol} / \mathrm{L}$ acetic acid-imidazole, $50 \mathrm{mg} / 100 \mathrm{~g}$ sodium benzoate, $\mathrm{pH}$ 7). Firstly, the resulting suspensions were stirred at room temperature until the protein was completely dissolved. The oily phase (10 g/100 g) and the aqueous phase $(90 \mathrm{~g} / 100 \mathrm{~g})$ were mixed using high-speed homogenization for $5 \mathrm{~min}$ under $13500 \mathrm{rpm}$ to form coarse emulsions. Finally, nanoemulsions were obtained by passing coarse emulsions through a microfluidizer (Microfluidics LM20, Microfluidics Corp., Newton, MA, USA) 5 times at $5 \times 10^{7} \mathrm{~Pa}$. The $\mathrm{pH}$ of the nanoemulsion was then immediately adjusted to 7.0. Each emulsion was produced in duplicate. All samples were stored in $100 \mathrm{~mL}$ sealed glass bottles at room temperature in the dark for physical stability evaluation. 


\subsection{Effect of carrier oil concentration}

The overall oil content of the nanoemulsions (TCA and carrier oil) was kept constant at 10

$127 \mathrm{~g} / 100 \mathrm{~g}$. TCA was mixed with MCT or LCT in different ratios $(100 / 0,90 / 10,70 / 30,50 / 50,30 / 70$

128 and $0 / 100, \mathrm{~m} / \mathrm{m}$ ) under stirring (15 min, $750 \mathrm{rpm})$. In order to study colloidal stability under storage,

129 the prepared nanoemulsions were stored for 28 days and characterized in terms of hydrodynamic

130 size and zeta potential as a function of time ranging from 1 day to one month.

\section{2.4. Droplet hydrodynamic size and size distribution}

Droplet size and size distribution were determined by dynamic light scattering using a Zetasizer Nano-ZS90 (Malvern Instruments, Worcestershire, UK) at fixed angle of $90^{\circ}$. To perform

134 measurement, nanoemulsions were diluted to an oil droplet concentration around $0.1 \mathrm{wt} \%$ using 135 imidazole acetate buffer to eliminate multiple scattering effects. After $90 \mathrm{~s}$ of equilibrium, each 136 sample was analyzed three times. Then the average droplet size and polydispersity index (PdI) were 137 obtained.

\subsection{Zeta potential $(\zeta)$}

Nanoemulsions were diluted to a concentration around $0.05 \mathrm{wt} \%$ with imidazole acetate

140 buffer to avoid multiple scattering effects. Diluted samples were transferred to the cell of 141 disposable cuvettes for electrophoretic mobility measurement (Malvern Instruments, 142 Worcestershire, UK). All measurements were performed three times and the $\zeta$-potential values 143 were reported as the average of three individual injections ( \pm SD (standard deviation)).

\subsection{Nanoemulsion stability to environmental stress}

According to preliminary results, nanoemulsions containing mixed oily phase in the ratio 146 TCA/MCT or LCT of 100/0 and 70/30 were investigated in the remainder of the study. The 
147 resultant nanoemulsions were referred to as T100, T70M30 and T70L30 according to their oil 148 compositions. To evaluate the effect of environmental stress on the properties of nanoemulsions, 149 different $\mathrm{pHs}$, salt concentrations, and temperatures were used to mimic scene which might be 150 experienced during manufacture, cooking or utilization. For each dispersion, droplet size 151 distribution and $\zeta$-potential of samples were measured.

152 pH stability: Nanoemulsion samples were adjusted to $\mathrm{pH}$ values from 9.0 to 3.0 by adding 1.0 $153 \mathrm{~mol} / \mathrm{L} \mathrm{HCl}$ or $1.0 \mathrm{~mol} / \mathrm{L} \mathrm{NaOH}$ and then stirred for $20 \mathrm{~min}$ to make sure the value of $\mathrm{pH}$ stable.

154 Salt stability: Nanoemulsion samples ( $\mathrm{pH}$ 7.0) were mixed with different ratios of $\mathrm{NaCl}$ solution 155 and distilled water while continuously stirring. The final $\mathrm{NaCl}$ concentration in the studied 156 nanoemulsions were $0,50,100$, and $300 \mathrm{mmol} / \mathrm{L}$. Oil content and emulsifier contents after dilution 157 were $5 \mathrm{~g} / 100 \mathrm{~g}$ and $0.5 \mathrm{~g} / 100 \mathrm{~g}$, respectively.

158 Temperature stability: Selected nanoemulsion samples $(\mathrm{pH} 7.0)$ were heated in a water bath at

159 different temperatures $60^{\circ} \mathrm{C}$ and $80{ }^{\circ} \mathrm{C}$ for $1 \mathrm{~h}$, and then cooled down to room temperature prior to 160 analysis. Nanoemulsions stored in refrigerator $\left(4^{\circ} \mathrm{C}\right)$ and at room temperature $\left(25^{\circ} \mathrm{C}\right)$ were used 161 as controls.

\section{$162 \quad$ 2.7. Viscosity}

Viscosity of nanoemulsions was measured by Viscometers (LP-22, Brookfield, Canada) at $164150 \mathrm{~s}^{-1}$ at ambient temperature. Sample volume $(0.5 \mathrm{~mL})$ was kept constant and each measurement 165 was repeated three times.

\subsection{Interfacial tension}

The oil-water interfacial tension was measured using an optical tensiometer equipped with an oscillating drop accessory (Tracker Teclis/IT Concept, France) at room temperature. In brief, 
169 the aqueous phase was placed in a glass cuvette, and the oil phase was injected into the aqueous

170 phase using a syringe. The shape of the oil drop formed was recorded using a high-speed digital

171 camera and the interfacial tension $(\mathrm{mN} / \mathrm{m})$ was calculated using the Tracker Software (Tracker

172 Teclis/IT Concept, France). According to the density of the oil phase, the rising drop method or 173 pendant drop method were used. Five different oil compositions (T100, T70M30, T70L30, M100

174 and L100) were studied and the initial volume of the oil drop was $\sim 15 \mu \mathrm{L}$. The aqueous phase 175 contained $0.005 \mathrm{wt} \%$ caseinate in imidazole-acetate buffer ( $\mathrm{pH} 7.0)$. The test was carried out at 176 room temperature for $7200 \mathrm{~s}$ and each experiment was run in triplicate.

\subsection{Antibacterial activity of nanoemulsions}

The "zone of inhibition" assay on solid media was used for the determination of the antimicrobial effects of nanoemulsions against Listeria innocua (ATCC 33090) and Escherichia coli (ATCC 10536). Strains were stored at $-20^{\circ} \mathrm{C}$ in Tryptone Soy Broth (TSB) (Biokar diagnostics, Beauvais, France) with glycerol $(15 \mathrm{~mL} / 100 \mathrm{~mL})$. One milliliter of the stock culture was transferred to $9 \mathrm{~mL}$ of TSB and incubated for $8 \mathrm{~h}$ at $37^{\circ} \mathrm{C}$. Then one milliliter of this pre-culture was transferred in $9 \mathrm{~mL}$ of TSB and incubated for $16 \mathrm{~h}$ at $37^{\circ} \mathrm{C}$. After that, pre-cultured bacteria were diluted in

184 TSB to a final concentration of $10^{6} \mathrm{CFU} / \mathrm{mL}$. One $\mathrm{mL}$ of bacterial suspension was incorporated at $1855 \mathrm{~mL} / 100 \mathrm{~mL}$ in melted Tryptone Soy Agar (TSA) and cooled in Petri dishes. A sterilized glass 186 pipette $(6 \mathrm{~mm}$ in diameter, Fisher Scientific) was used to make a well in the TSA Petri dishes 187 inoculated. To maintain the same TCA concentration, $50 \mu \mathrm{L}$ of T70M30 and T70L 30 and $35 \mu \mathrm{L}$ 188 of T100 were placed in different wells. M100, L100, pure MCT and pure LCT were used as controls.

189 The Petri dishes were then incubated for $2 \mathrm{~h}$ at $4{ }^{\circ} \mathrm{C}$ for making nanoemulsion diffusion and then 190 incubated at $37^{\circ} \mathrm{C}$. Inhibition zone diameter was measured after $24 \mathrm{~h}$ and each experiment was 191 repeated three times. 


\section{$192 \quad 2.10$. Statistical analysis}

193 All assays were performed at least in triplicate. The data were presented as means \pm 194 standard deviation of different samples. Statistical analyses were performed using one-way analysis 195 of variance and multiple comparisons of means were done by Fishers Least Significant Difference 196 (LSD) test. Statistical significance was defined as $\mathrm{p}<0.05$. 


\section{Results and discussion}

198

\subsection{Effect of carrier oil content on the properties of TCA nanoemulsions}

The mean droplet size and polydispersity index of nanoemulsions containing different ratios of TCA/carrier oil $(100 / 0,90 / 10,70 / 30,50 / 50,30 / 70$ and 0/100) stored during 4 weeks were measured and the obtained results are reported in Fig. 1. Initially, all nanoemulsions had relatively small average hydrodynamic particle diameters ranging between $105.7 \sim 211.3 \mathrm{~nm}$, and the lowest droplet size was obtained at the ratio TCA/LCT of 90/10. Except for nanoemulsions containing pure TCA (100/0), the other nanoemulsions have lower PdI value $(<0.15)$ after one day storage. Low PdI value indicated that the droplet are narrowly size distributed. According to Stokes law, the smaller the droplet size was, the lower the sedimentation or creaming rate was (Paraskevopoulou et al., 2005). For nanoemulsions containing pure TCA, a transparent layer was detected in the top of the sample indicating the movement of the oil droplets to the bottom of the test tube during storage (data not shown). Results showed that, when the content of carrier oil was above $30 \%$ in the oil phase, caseinate-coated nanoemulsions containing the mixed oil phase can remain stable for a long time ( $>28$ days), which suggests that they were stable to Oswald ripening, coalescence, and flocculation. In fact, it is known that low size of droplets is more prone to Ostwald ripening during storage, i.e., diffusion of oil molecules from the smaller to the larger droplets (McClements et al., 2012, p.; Wooster et al., 2008). For this reason, it is possible for small droplets to be produced during homogenization process and then grow rapidly during storage. In our case, increased droplet size and relatively higher PdI value were present in the nanoemulsions containing oil phases with 100\% and 90\% TCA after two weeks. This is in agreement with results obtained for nanoemulsions containing pure thyme oil which was attributed to Ostwald ripening (Chang et al., 2012). In addition, it is worth noting that, by comparing the PdI values of nanoemulsions 
containing mixed oil phase of the 70/30, LCT as a carrier oil showed lower value of PdI than that

221 of MCT, which may be attribute to the difference in properties between the two carriers. Similar

222 results were reported by McClements (2012) who concluded that the properties of the droplets

223 produced during homogenization depends on the viscosity and interfacial tension of the lipid phase.

224 Compared to nanoemulsions containing TCA, the improved stability observed after

225 addition of a carrier oil could be attributed to a decrease in the solubility of the oily phase causing

226 a drop in Ostwald ripening. In fact, TCA is slightly soluble in water (Seraj \& Seyedarabi, 2019),

227 while MCT and LCT have a relatively low water-solubility. Thus, the carrier oil can act as a

228 ripening inhibitor through an entropy of mixing effect during homogenization (McClements et al.,

229 2012). Density of oil is another factor that may affect the formation and stability of nanoemulsions.

230 In fact, TCA has a higher density $\left(1050 \mathrm{~kg} \cdot \mathrm{m}^{-3}\right)$ than water $\left(997 \mathrm{~kg} \cdot \mathrm{m}^{-3}\right)$ at $25^{\circ} \mathrm{C}$, while MCT

$231\left(945 \mathrm{~kg} \cdot \mathrm{m}^{-3}\right)$ and LCT $\left(920 \mathrm{~kg} \cdot \mathrm{m}^{-3}\right)$ have a relatively lower density than water. The density of the

232 mixed oil phase could be consequently close to that of the water phase which can reduce droplet

233 creaming and sedimentation during long time storage. In addition, strong electrostatic repulsions

234 between caseinate coated oil droplets is another important factor of nanoemulsion stability. On the

235 other hand, the mean particle diameter of nanoemulsion increased with increasing carrier oil

236 content in the organic phase, which could be probably attributed to the decreased diffusion of TCA

237 from the oil droplets, resulting in an increase of particle diameter after homogenization.

238 To further explore the effect of the properties of carrier oil on the stability of nanoemulsions,

239 the viscosity of nanoemulsions containing mixed oil phases in the ratio $100 / 0$ and $70 / 30$ were

240 investigated (Fig. 2a). According to the results reported in this figure and measured at $22{ }^{\circ} \mathrm{C}$, pure

241 LCT showed highest viscosity (30.68 mPa.s), while pure TCA showed the lowest one (5.08 mPa.s)

242 and the mixtures TCA/MCT and TCA/LCT showed intermediate viscosity values (7.56 mPa.s and 
$2439.87 \mathrm{mPa} . \mathrm{s}$, respectively). Therefore, the addition of carrier oil significantly increased the viscosity 244 of the oily phase. As stated by Qian et al., (2011), the increased viscosity could improve stability 245 of nanoemulsions, but their droplet size will be slight increased, which was consistent with our 246 previous results (Fig. 1). Fig. 2b showed the interfacial tension reduction kinetics between different 247 oily phases and sodium caseinate aqueous solution. Whatever the oily phase composition, the 248 interfacial tension decreased over time, which can be attributed to the adsorption of caseinate 249 molecules to the oil-water interface. Pure LCT and pure MCT showed that the equilibrium 250 interfacial tensions were relatively high (around $10.9 \mathrm{mN} / \mathrm{m}$ and $7.3 \mathrm{mN} / \mathrm{m}$, respectively), while 251 pure TCA showed an equilibrium interfacial tension around $2.7 \mathrm{mN} / \mathrm{m}$. This result can be attributed 252 to the difference in polarity between TCA, LCT and MCT. Interestingly, the equilibrium interfacial 253 tensions of the two mixed oil systems showed almost the same equilibrium interfacial tensions than 254 that of pure TCA, suggesting that the interfacial tension between oil and water was mainly 255 dependent on the presence of TCA. Similar results were found by Chen et al. (2018) as well as 256 Felix et al. (2019). Indeed, Chen et al. (2018) found that, in the presence of TCA, the surface of the 257 oil droplets stabilized by whey protein became crinkly, while the shape of the oil droplets without 258 TCA did not change. This result indicates that TCA has the ability to improve the adsorption of 259 caseinate to the oil/water interface, resulting in smaller size oil droplets after homogenization (Fig. $2601)$.

As shown in Fig. 3, the $\zeta$-potential of the nanoemulsions containing the two different carrier 262 oils were measured within 4 weeks. At the first day, all nanoemulsions had a relatively high 263 negative surface potential $(-50$ to $-30 \mathrm{mV})$, which can be attributed to the fact that the aqueous 264 phase $\mathrm{pH}$ (7.0) during the preparing process was above the isoelectric point of the caseinate 265 molecules (Wang, Dumas, \& Gharsallaoui, 2019). As described by Lieberman and Rieger (2008), 
when the absolute value of $\zeta$-potential is greater than $25 \mathrm{mV}$, the electrostatic repulsions are high

267 enough to maintain good colloidal stability of the prepared emulsion. Thus, it could be deduced that the presence of caseinate could provide high repulsive forces between the droplets to have good physical stability whatever the oil composition. However, the surface potential of oil droplets changed significantly after one week, especially for nanoemulsions containing pure TCA or a low amount of carrier oil (T90M10 and T90L10), which could indicate a change in the interface composition and/or structure. became more negative with increasing carrier oil content, which means that the electrostatic repulsions between oil droplets are more intense when the carrier oil content was increased. Several

276 different physicochemical mechanisms might account for the observed changes in surface charge 277 of nanoemulsions. Firstly, the composition and structure of the adsorbed caseinate layer may 278 depend on the properties of the oil phase (such as size, polarity and viscosity), which could 279 indirectly change their surface potential (li Zhai et al., 2013). Secondly, there is a hypothesis that 280 TCA may have chemically reacted with the adsorbed caseinate due to the presence of an aldehyde 281 group in TCA molecules generally used as a cross-linking agent (Marin et al., 2014), and then 282 changed their structure and electrical characteristics. Thirdly, there may be charged surface-active 283 impurities in TCA, MCT and LCT that may affect the electrical properties of the droplets. Finally, 284 as stated by Zhu (2017), cinnamaldehyde can rapidly be oxidized to cinnamic acid (Fig.1. 285 Supplementary data) during storage. Thus, the presence of cinnamic acid can affect the 286 environmental properties, like $\mathrm{pH}$, and then affect the $\zeta$-potential of caseinate coated droplets.

To explore this perspective, five nanoemulsions containing different oil mixtures (T100, 288 T70M30, T70L30, T0M100 and T0L100) were selected and the pH of each sample was measured 
within 4 weeks (Fig. 4). The pH of nanoemulsions containing pure TCA or mixtures of TCA and

290 carrier oils decreased with storage time, while the $\mathrm{pH}$ of nanoemulsions containing pure carrier oils

291 (MCT and LCT) remained unchanged. This result can also explain the fact that the zeta potential

292 of nanoemulsions containing high contents of carrier oil was relatively stable (Fig.3). Interestingly,

293 compared to pure TCA nanoemulsions, the nanoemulsions containing mixed oil phase (T70M30

294 and T70L30) appeared to be able to slow down the $\mathrm{pH}$ to the same extent after three weeks. In

295 addition, LCT as carrier oil in nanoemulsions exhibited more ability $(\mathrm{p}<0.05)$ to change the $\mathrm{pH}$

296 than MCT as carrier oil. This result can be explained by comparing the changes in PdI values of

297 T70M30 and T70L30 as a function of time (Fig. 1c and Fig. 1d). In fact, a significant increase of

298 PdI value was found when MCT was used as carrier oil after one week, while the PdI of T70L30

299 nanoemulsions remained stable. These effects may therefore depend on the physical properties of

300 carrier oils. Similar tendency was also reported by Walker (2017) who found that the oxidation rate

301 of fish oil was dependent on the carrier oil type.

\subsection{Physical stability of nanoemulsions against environmental stress}

Caseinate stabilized nanoemulsions are especially sensitive to environmental conditions

which could affect their physical stability. The main three influencing parameters are $\mathrm{pH}$, ionic strength, and temperature whose effects have been studied in the following sections.

pH stability: Three different pHs (3.0, 7.0 and 11.0) were used to study the effect of $\mathrm{pH}$ on the stability of nanoemulsions (Fig. 5). As shown in Fig. 5a, no significant difference was found in particle size of the three samples prepared at different $\mathrm{pH}$ values. For droplet size distribution, nanoemulsions containing mixed oil phases showed very low PdI values indicating that they were highly concentrated, while nanoemulsions containing pure TCA showed very high PdI values in each $\mathrm{pH}$ condition. In fact, as the $\mathrm{pH}$ increased from 3.0 to 11.0, the particle size of the three 
312 nanoemulsions slightly increased. This may be attributed to the electrostatic repulsion forces

313 among amino and carboxyl groups of caseinate (Lovett et al., 2015). On the other hand, aqueous

$314 \mathrm{pH}$ is related to the solubility of caseinate which will affect the particle size distribution of

315 nanoemulsions after homogenization. As stated by Mezdour et al. (2008), the increase of the

316 caseinate solubility allows to form thicker adsorption oil-in-water layer. The $\zeta$-potential of the

317 droplets in these emulsions was also evaluated (Fig. 5b). For all samples, the $\zeta$-potential showed

318 the similar trend and changed from positive to negative as the $\mathrm{pH}$ changed from 3 to 9 , which can

319 be attributed to the fact that the isoelectric point (Ip) of caseinate is around 4.5. The results are

320 consistent with our previous studies that have shown that caseinate-coated oil droplets are highly

321 unstable and aggregate in the vicinity of this $\mathrm{pH}$ (Wang et al., 2019). This result also showed that

$322 \zeta$-potential of emulsions mainly depends on the caseinate whatever the composition of the oily 323 phase.

324 Ionic force: Nanoemulsions can be used as delivery systems in some food matrices containing 325 different salt concentrations, and therefore it is important to verify the effect of ionic strength on 326 droplet stability. Thus, the effect of different $\mathrm{NaCl}$ concentrations on the mean particle diameter 327 and $\zeta$-potential of nanoemulsions was examined (Fig. 6). All nanoemulsions showed an increase 328 of the droplet size and $\mathrm{PdI}$ when $\mathrm{NaCl}$ concentration was increased for 0 to $300 \mathrm{mmol} / \mathrm{L}$, especially 329 for nanoemulsions containing pure TCA ( $<<0.05$, significantly). For nanoemulsions containing 330 mixed oily phases, addition of low content of salt $(<200 \mathrm{mmol} / \mathrm{L})$ to the nanoemulsions caused 331 little changes in the mean particle diameter after homogenization, but addition of higher salt content 332 promoted a certain degree of droplet aggregation $(\mathrm{p}<0.05)$. This droplet aggregation observed at higher 333 salt concentrations is due to a reduction in the electrostatic repulsion between the protein-coated droplets 334 caused by electrostatic screening and ion binding effects 
336 Similar phenomenon was found upon addition of $\mathrm{NaCl}$ to $\beta$-lactoglobulin-stabilized emulsions

337 (Qian et al., 2011). Moreover, our results showed that, in the presence of $\mathrm{NaCl}$, the droplet size of

338 nanoemulsions containing pure TCA turned to bimodal distribution (two peaks in one curve, data

339 not shown), while the particle size distributions of nanoemulsions containing mixtures of TCA and

340 carrier oil remained monomodal, though their peak shapes and locations were changed slightly.

341 Thus, addition of carrier oil can prevent the emulsions to form bimodal distributions, which was

342 consistent with the results obtained by Zhao et al. (2015). This phenomenon can be attributed to

343 the fact that an increase in particle size leads to an increase in the rate of creaming of droplets in

344 nanoemulsions (Paraskevopoulou et al., 2005). Fig. 6b showed that the $\zeta$-potential of

345 nanoemulsions was significantly affected by ionic strength. All samples showed a decrease trend

346 when the $\mathrm{NaCl}$ concentration was increased suggesting an accumulation of counter-ions around oil

347 droplets surfaces screening caseinate charged groups preventing repulsions between oil droplets

348 (Öztürk, 2017).

349 Temperature stability: In many commercial applications, it seems important that emulsions can

350 withstand high temperatures during their production, storage or use. For this reason, the effect of

351 heating treatments $\left(60^{\circ} \mathrm{C}\right.$ and $\left.80{ }^{\circ} \mathrm{C}\right)$ on the stability of nanoemulsions was examined, and $4{ }^{\circ} \mathrm{C}$ as

352 well as $25{ }^{\circ} \mathrm{C}$ were used as control (Fig. 7). With the exception of pure TCA-containing

353 nanoemulsions treated at $80^{\circ} \mathrm{C}$, all other nanoemulsions appeared to be relatively stable to heat

354 treatment and showed a unimodal particle size distribution (Fig. 7a). This could be attributed to the

355 good thermal stability of caseinate-coated droplets owing to their relatively high negative charge

356 at $\mathrm{pH} \mathrm{7,} \mathrm{which} \mathrm{led} \mathrm{to} \mathrm{stronger} \mathrm{electrostatic} \mathrm{repulsions} \mathrm{between} \mathrm{them.} \mathrm{Meanwhile,} \mathrm{caseinate}$

357 stabilized emulsions generally have better stability during heating, because of the protein structure 
358 which does not affected by the heat-induced conformation changes as for globular proteins

359 (Srinivasan et al., 2002). For nanoemulsions containing pure TCA, a slight increase in size was

360 observed at $60{ }^{\circ} \mathrm{C}$, but when the heating temperature was increased to $80{ }^{\circ} \mathrm{C}$, the size increased

361 significantly $(\mathrm{p}<0.05)$. After heating, the $\zeta$-potential of nanoemulsions were also measured.

362 According to Fig. 7b, there was no significant change in the $\zeta$-potential for all nanoemulsions upon

363 thermal treatments, suggesting that heating did not strongly influence the overall composition or

364 structure of the caseinate coatings. The extreme condition may affect the physical stability of the

365 nanoemulsion, however, MCT oil and LCT oil as carrier oils into the oil phase showed better

366 tolerance than pure TCA.

\section{3.3. Antibacterial activity of nanoemulsions}

Nanoemulsions were studied for their antibacterial activity against a Gram-positive

369 (Listeria innocua) and a Gram-negative (Escherichia coli) bacteria. Based on the same TCA

370 content, three nanoemulsions (T100, T70M30 and T70L30) were added to each well of the

371 bacterial-containing medium, and the same formulation without TCA as a control. Inhibition zones

372 of nanoemulsions on medium containing bacteria after $24 \mathrm{~h}$ is shown in Fig. 8a. The three

373 nanoemulsions showed clear inhibition zones against the two bacteria, whereas the control without

374 TCA showed no inhibition zones. The size of the inhibition zones was measured by the software

375 Image $\mathrm{J}$ (National Institutes of Health, USA) and the obtained values are shown in Fig. 8b. The

376 antimicrobial activity of TCA is attributed to its aldehyde functional group and the antibacterial

377 mechanism of TCA is probably due to the increase in permeability of bacteria cell wall (Doyle \&

378 Stephens, 2019b). As stated by Weiss et al. (2009), encapsulation of TCA at the nanoscale could

379 increase the physical stability of bioactive compounds and increases their bioactivity through 380 activation of cell absorption mechanism. In addition, there was no significant disparity between 
381 antimicrobial activity of nanoemulsions containing MCT and LCT as carrier oils, but these two 382 nanoemulsions exhibited larger inhibition zones than nanoemulsions containing pure TCA $383(p<0.05)$. This phenomenon can be attributed to the fact that the addition of a carrier oil increases 384 emulsion stability during storage, which can further increase its biological activity. Another reason 385 may be considered to explain this result, is that nanoemulsions containing pure TCA may loss a 386 small amount of TCA, because TCA is volatile and subject to oxidation. Meanwhile, the size of 387 inhibition zones can be affected by several parameters, such as the amount of nanoemulsion, the 388 spread area of nanoemulsions, the mechanism of TCA release, the number of bacteria in the 389 medium, and the time of measuring inhibition zone. As far as possible, we have tried in this work 390 to keep all these parameters constant and to vary only the composition of the emulsion in order to 391 detect the effect of the carrier oil. 


\section{Conclusions}

This study compared the ability of two different carrier oils to improve the properties of

394 emulsions containing trans-cinnamaldehyde and stabilized by sodium caseinate. The influence of

395 the oil type and content on the physical stability of nanoemulsions was investigated under different

396 pHs, salt concentrations and temperature as well as their antibacterial activity against two common

397 gram-positive and gram-negative bacteria. The analyses revealed that stable caseinate-coated

398 nanoemulsions are difficult to formulate using pure TCA. However, nanoemulsions containing

399 TCA mixed with carrier oil could keep stable for a relatively long period, especially when LCT is

400 used as carrier oil. This stability improvement can be attributed to a reduction of TCA diffusion in

401 the aqueous phase and an inhibition of Ostwald ripening. Antibacterial effect revealed that,

402 compared to nanoemulsions containing pure TCA, the activity of nanoemulsions containing

403 mixtures of TCA and carrier oils exhibited better antibacterial activity against Escherichia coli and

404 Listeria innocua. The development of these nanoemulsions is in line with the growing interest of

405 the food industry and consumers in using products based on natural substances and the

406 incorporation of carrier oils into nanoemulsion-based systems containing TCA is a promising

407 technique that can extend the shelf life of perishable foods. 


\section{Reference}

Adams, T. B., Cohen, S. M., Doull, J., Feron, V. J., Goodman, J. I., Marnett, L. J., Munro, I. C., Portoghese, P. S., Smith, R. L., \& Waddell, W. J. (2004). The FEMA GRAS assessment of cinnamyl derivatives used as flavor ingredients. Food and Chemical Toxicology, 42(2), $157-185$.

Chang, Y., McLandsborough, L., \& McClements, D. J. (2012). Physical properties and antimicrobial efficacy of thyme oil nanoemulsions: Influence of ripening inhibitors. Journal of Agricultural and Food Chemistry, 60(48), 12056-12063.

Chen, E., Cao, L., McClements, D. J., Liu, S., Li, B., \& Li, Y. (2018). Enhancement of physicochemical properties of whey protein-stabilized nanoemulsions by interfacial crosslinking using cinnamaldehyde. Food Hydrocolloids, 77, 976-985. https://doi.org/10.1016/j.foodhyd.2017.11.047

Choi, S. J., Decker, E. A., Henson, L., Popplewell, L. M., \& McClements, D. J. (2009). Stability of citral in oil-in-water emulsions prepared with medium-chain triacylglycerols and triacetin. Journal of Agricultural and Food Chemistry, 57(23), 11349-11353.

Donsì, F., Annunziata, M., Sessa, M., \& Ferrari, G. (2011). Nanoencapsulation of essential oils to enhance their antimicrobial activity in foods. LWT-Food Science and Technology, 44(9), 1908-1914.

Donsì, F., Annunziata, M., Vincensi, M., \& Ferrari, G. (2012). Design of nanoemulsion-based delivery systems of natural antimicrobials: Effect of the emulsifier. Biotechnology for Enhancing Plant Production and Food Quality - IBS 2010 Part III, 159(4), 342-350.

Doyle, A. A., \& Stephens, J. C. (2019a). A review of cinnamaldehyde and its derivatives as antibacterial agents. Fitoterapia, 139, 104405.

Doyle, A. A., \& Stephens, J. C. (2019b). A review of cinnamaldehyde and its derivatives as antibacterial agents. Fitoterapia, 139, 104405.

Felix, M., Yang, J., Guerrero, A., \& Sagis, L. M. C. (2019). Effect of cinnamaldehyde on interfacial rheological properties of proteins adsorbed at O/W interfaces. Food Hydrocolloids, 97,

Jo, Y.-J., Chun, J.-Y., Kwon, Y.-J., Min, S.-G., Hong, G.-P., \& Choi, M.-J. (2015). Physical and antimicrobial properties of trans-cinnamaldehyde nanoemulsions in water melon juice. LWT-Food Science and Technology, 60(1), 444-451. 
Julian McClements, D., Henson, L., Popplewell, L. M., Decker, E. A., \& Jun Choi, S. (2012). Inhibition of Ostwald ripening in model beverage emulsions by addition of poorly water soluble triglyceride oils. Journal of Food Science, 77(1), C33-C38.

li Zhai, J., Day, L., Aguilar, M.-I., \& Wooster, T. J. (2013). Protein folding at emulsion oil/water interfaces. Current Opinion in Colloid \& Interface Science, 18(4), 257-271.

Lieberman, H. A., \& Rieger, M. M. (2008). Pharmaceutical dosage forms: Disperse systems. Informa,.

Lovett, J. R., Warren, N. J., Ratcliffe, L. P., Kocik, M. K., \& Armes, S. P. (2015). pH-responsive non-ionic diblock copolymers: Ionization of carboxylic acid end-groups induces an orderorder morphological transition. Angewandte Chemie International Edition, 54(4), 12791283.

Marin, L., Moraru, S., Popescu, M.-C., Nicolescu, A., Zgardan, C., Simionescu, B. C., \& Barboiu, M. (2014). Out-of-Water Constitutional Self-Organization of Chitosan-Cinnamaldehyde Dynagels. Chemistry-A European Journal, 20(16), 4814-4821.

McClements, D. J., Henson, L., Popplewell, L. M., Decker, E. A., \& Choi, S. J. (2012). Inhibition of Ostwald Ripening in Model Beverage Emulsions by Addition of Poorly Water Soluble Triglyceride Oils. Journal of Food Science, 77(1), C33-C38.

McClements, D. J., \& Rao, J. (2011). Food-grade nanoemulsions: Formulation, fabrication, properties, performance, biological fate, and potential toxicity. Critical Reviews in Food Science and Nutrition, 51(4), 285-330.

Mezdour, S., Boyaval, P., \& Korolczuk, J. (2008). Solubility of $\alpha$ S1-, $\beta$-and $\kappa$-casein in waterethanol solutions. Dairy Science \& Technology, 88(3), 313-325.

Mochida, K., Gomyoda, M., Fujita, T., \& Yamagata, K. (1988). Toxicity of allyl isothiocyanate and cinnamic aldehyde assessed using cultured human KB cells and yeast, Saccharomyces cervisiae. Bull. Environ. Contam. Toxicol.;(United States), 40(3).

Mooyottu, S., Kollanoor-Johny, A., Flock, G., Bouillaut, L., Upadhyay, A., Sonenshein, A., \& Venkitanarayanan, K. (2014). Carvacrol and trans-cinnamaldehyde reduce Clostridium difficile toxin production and cytotoxicity in vitro. International Journal of Molecular Sciences, 15(3), 4415-4430. 
Öztürk, B. (2017). Nanoemulsions for food fortification with lipophilic vitamins: Production challenges, stability, and bioavailability. European Journal of Lipid Science and Technology, 119(7), 1500539.

Paraskevopoulou, A., Boskou, D., \& Kiosseoglou, V. (2005). Stabilization of olive oil-lemon juice emulsion with polysaccharides. Food Chemistry, 90(4), 627-634.

Polychniatou, V., \& Tzia, C. (2018). Evaluation of surface-active and antioxidant effect of olive oil endogenous compounds on the stabilization of water-in-olive-oil nanoemulsions. Food Chemistry, 240, 1146-1153.

Qian, C., Decker, E. A., Xiao, H., \& McClements, D. J. (2011). Comparison of biopolymer emulsifier performance in formation and stabilization of orange oil-in-water emulsions. Journal of the American Oil Chemists' Society, 88(1), 47-55.

Qian, C., \& McClements, D. J. (2011). Formation of nanoemulsions stabilized by model foodgrade emulsifiers using high-pressure homogenization: Factors affecting particle size. Food Hydrocolloids, 25(5), 1000-1008.

Riquelme, N., Zúñiga, R. N., \& Arancibia, C. (2019). Physical stability of nanoemulsions with emulsifier mixtures: Replacement of tween 80 with quillaja saponin. LWT - Food Science and Technology, 111, 760-766.

Saeed, F., Afzaal, M., Tufail, T., \& Ahmad, A. (2019). Use of natural antimicrobial agents: A safe preservation approach. Act Antimicrob Food Packag, Published-online.

Seraj, Z., \& Seyedarabi, A. (2019). The role of cinnamaldehyde and phenyl ethyl alcohol as two types of precipitants affecting protein hydration levels. International Journal of Biological Macromolecules.

Shreaz, S., Wani, W. A., Behbehani, J. M., Raja, V., Irshad, M., Karched, M., Ali, I., Siddiqi, W. A., \& Hun, L. T. (2016). Cinnamaldehyde and its derivatives, a novel class of antifungal agents. Fitoterapia, 112, 116-131.

Srinivasan, M., Singh, H., \& Munro, P. A. (2002). Formation and stability of sodium caseinate emulsions: Influence of retorting (121 C for $15 \mathrm{~min}$ ) before or after emulsification. Food Hydrocolloids, 16(2), 153-160.

Walker, R. M., Gumus, C. E., Decker, E. A., \& McClements, D. J. (2017). Improvements in the formation and stability of fish oil-in-water nanoemulsions using carrier oils: MCT, thyme oil, \& lemon oil. Journal of Food Engineering, 211, 60-68. 
498 Wang, J., Dumas, E., \& Gharsallaoui, A. (2019). Low Methoxyl pectin / sodium caseinate complexing behavior studied by isothermal titration calorimetry. Food Hydrocolloids, 88 , $163-169$.

501 Weiss, J., Gaysinsky, S., Davidson, M., \& McClements, J. (2009). Nanostructured encapsulation systems: Food antimicrobials. In Global issues in food science and technology (pp. 425479). Elsevier.

504 Wooster, T. J., Golding, M., \& Sanguansri, P. (2008). Impact of Oil Type on Nanoemulsion 505 Formation and Ostwald Ripening Stability. Langmuir, 24(22), 12758-12765.

Zhao, X., Liu, F., Ma, C., Yuan, F., \& Gao, Y. (2015). Effect of carrier oils on the physicochemical properties of orange oil beverage emulsions. Food Research International, 74, 260-268.

Zhu, R., Liu, H., Liu, C., Wang, L., Ma, R., Chen, B., Li, L., Niu, J., Fu, M., \& Zhang, D. (2017). Cinnamaldehyde in diabetes: A review of pharmacology, pharmacokinetics and safety. 
512 Table 1. General physical properties of TCA, MCT and LCT.

\begin{tabular}{lccc}
\hline Properties & $\begin{array}{c}\text { (TCA) trans- } \\
\text { Cinnamaldehyde }\end{array}$ & MCT & $\begin{array}{c}\text { LCT } \\
\text { (Sunflower oil) }\end{array}$ \\
\hline Density $\left(\mathrm{g} / \mathrm{cm}^{3}\right)$ & 1.05 & 0.945 & 0.920 \\
Viscosity $(\mathrm{mPa} . \mathrm{s})$ & 5.08 & 22.88 & 30.68 \\
Interfacial tension $(\mathrm{mN} / \mathrm{m})$ & 2.70 & 7.30 & 10.90 \\
Solubility in water $(\mathrm{mg} / 100 \mathrm{~mL})$ & 1.42 & Insoluble & Insoluble \\
\hline
\end{tabular}

513

514 

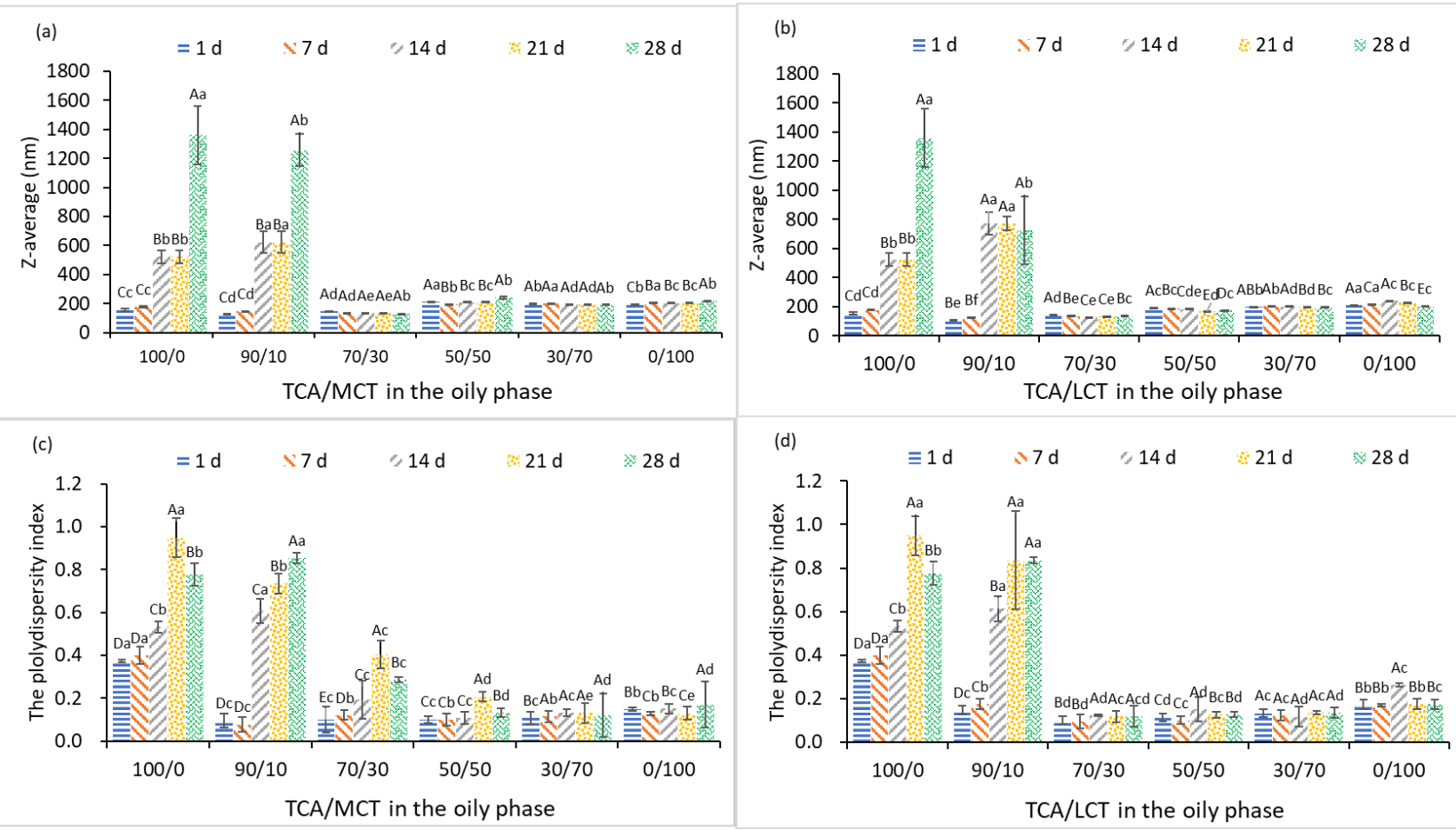

Fig.1. Effect of MCT or LCT content on particle size (a and b) and polydispersity index (c and d) of 


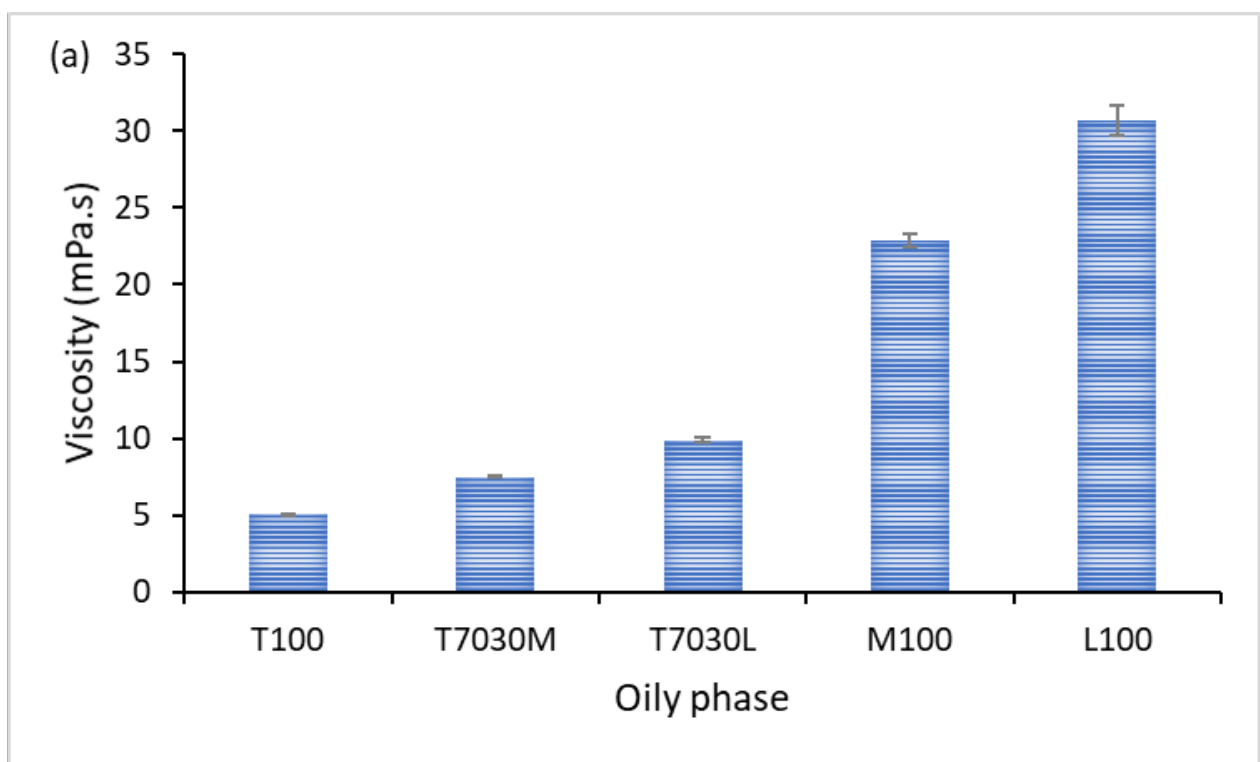

(b) $\rightarrow$ T100 $\rightarrow$ T70M30 $\multimap$ T70L30 $\rightarrow$ M100 $\leftarrow$ L100

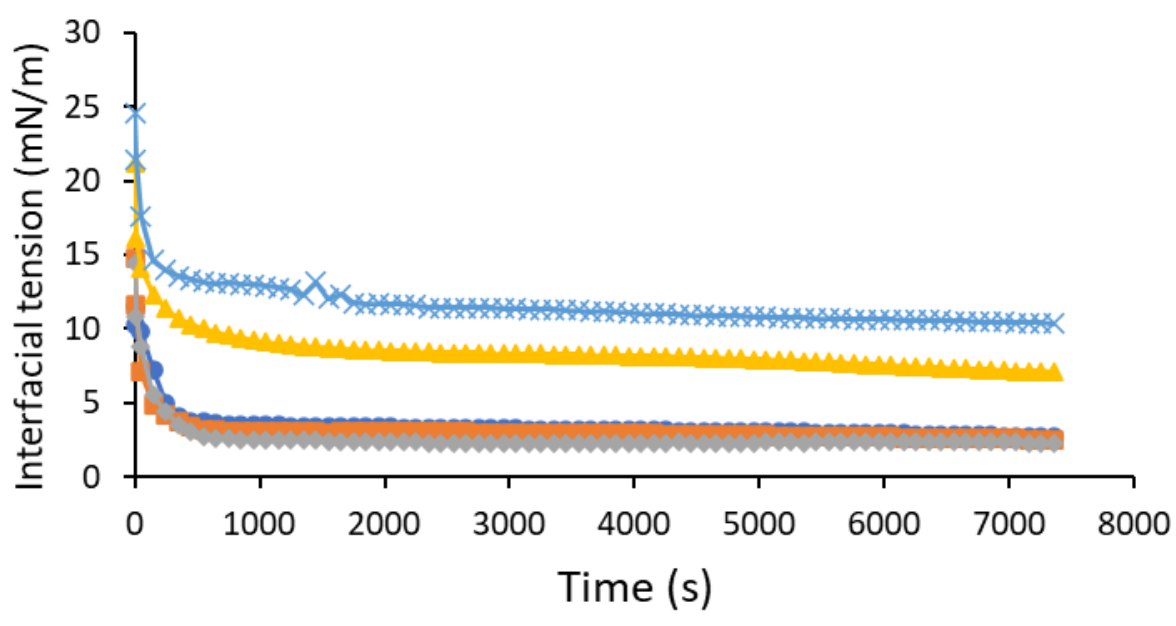

523 Fig. 2. Viscosity of five different oil compositions (a) and interfacial tension over time of five different oil compositions in the presence of $0.005 \mathrm{wt} \%$ sodium caseinate in the aqueous phase (b). 


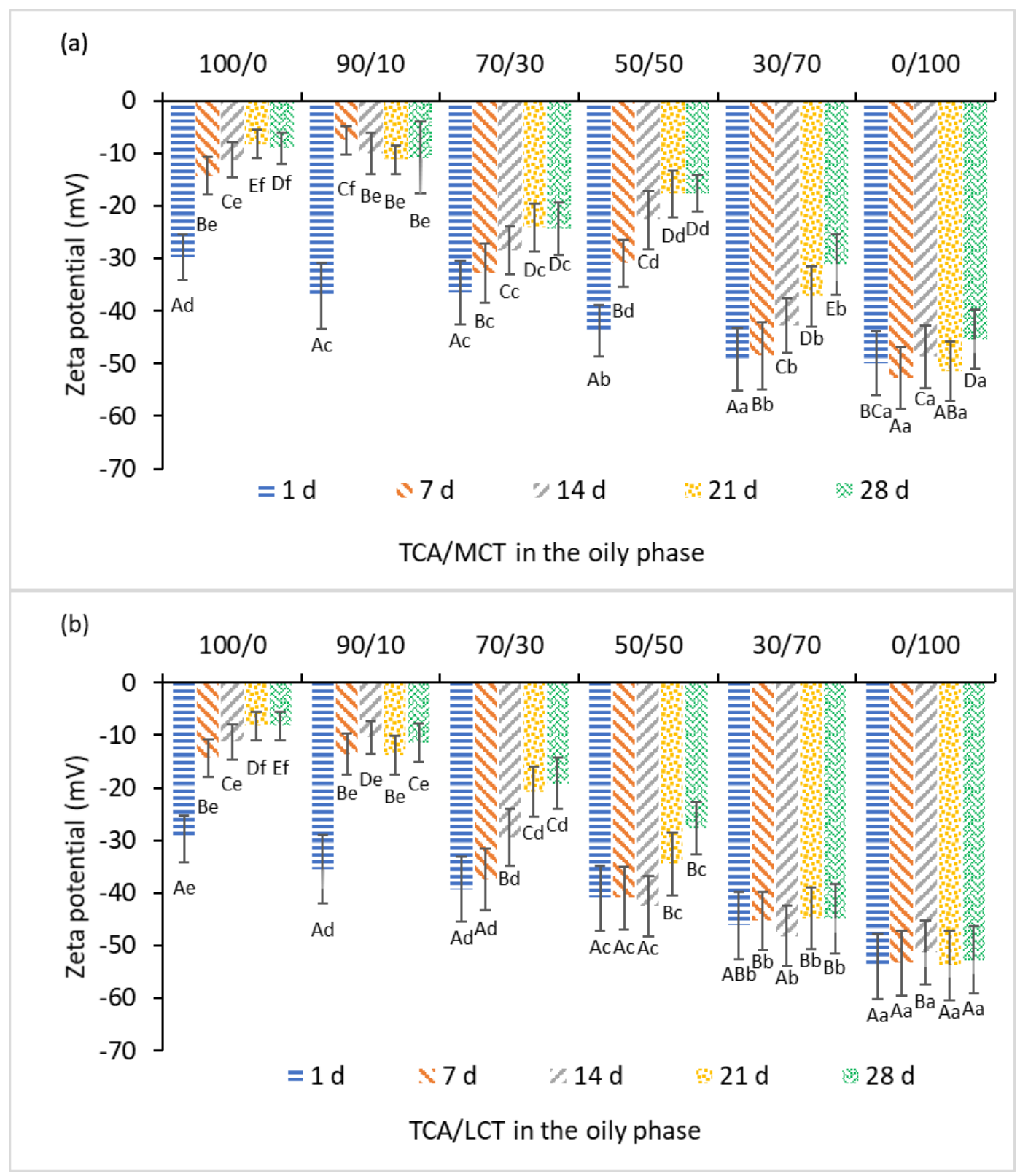

526 Fig.3. Effect of MCT(a) or LCT (b) content on the $\zeta$-potential of caseinate stabilized TCA nanoemulsions 527 as a function of storage time. Samples with different uppercase superscripts (A-E) differ significantly ( $p<$ 528 0.05) when different nanoemulsions are compared at same storage time; Samples with different lowercase 529 superscripts $(\mathrm{a}-\mathrm{f})$ differ significantly $(p<0.05)$ when the same nanoemulsion is compared at different 530 storage times. 


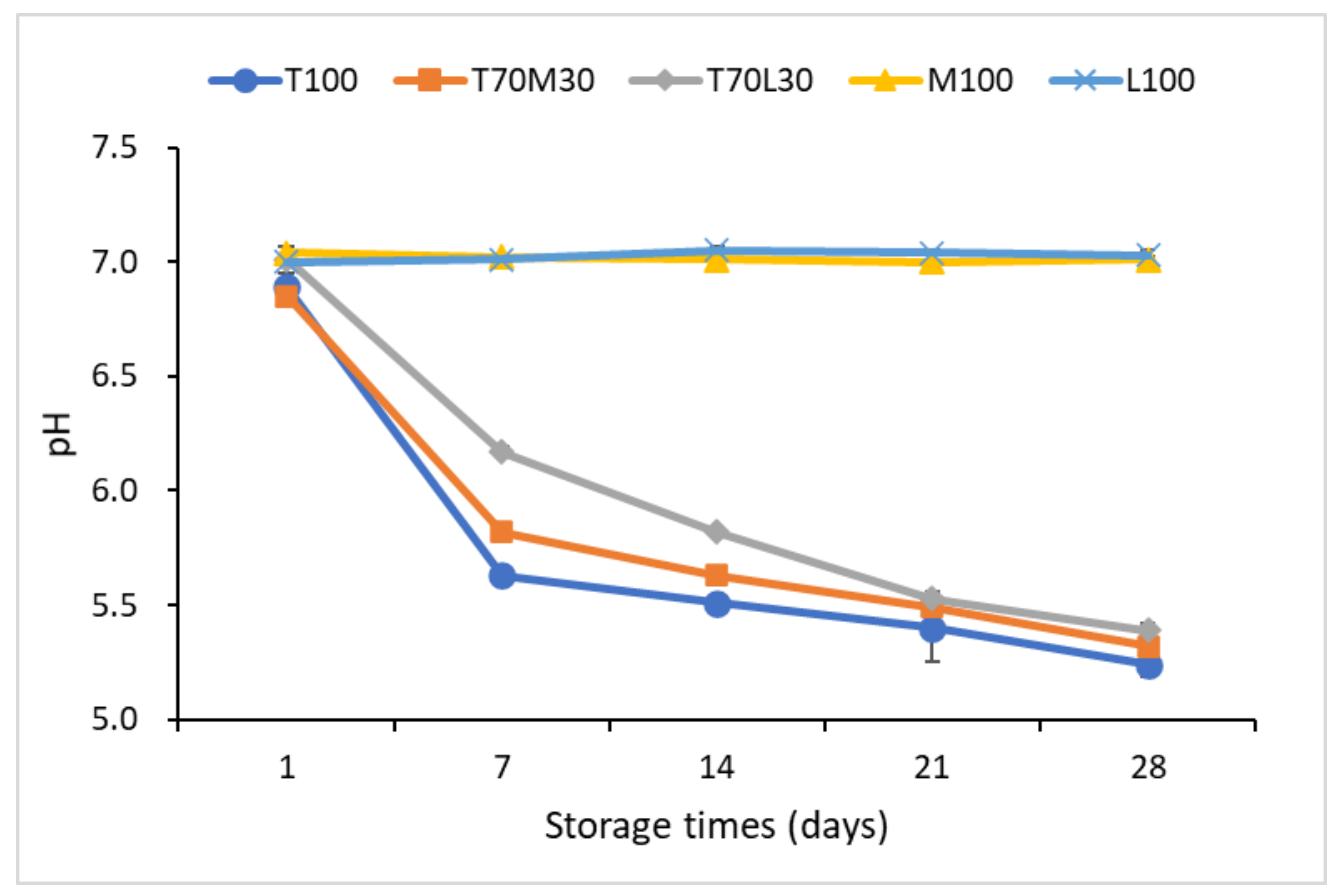

534 Fig. 4. $\mathrm{pH}$ values of caseinate stabilized nanoemulsions containing different oily phases during storage. 

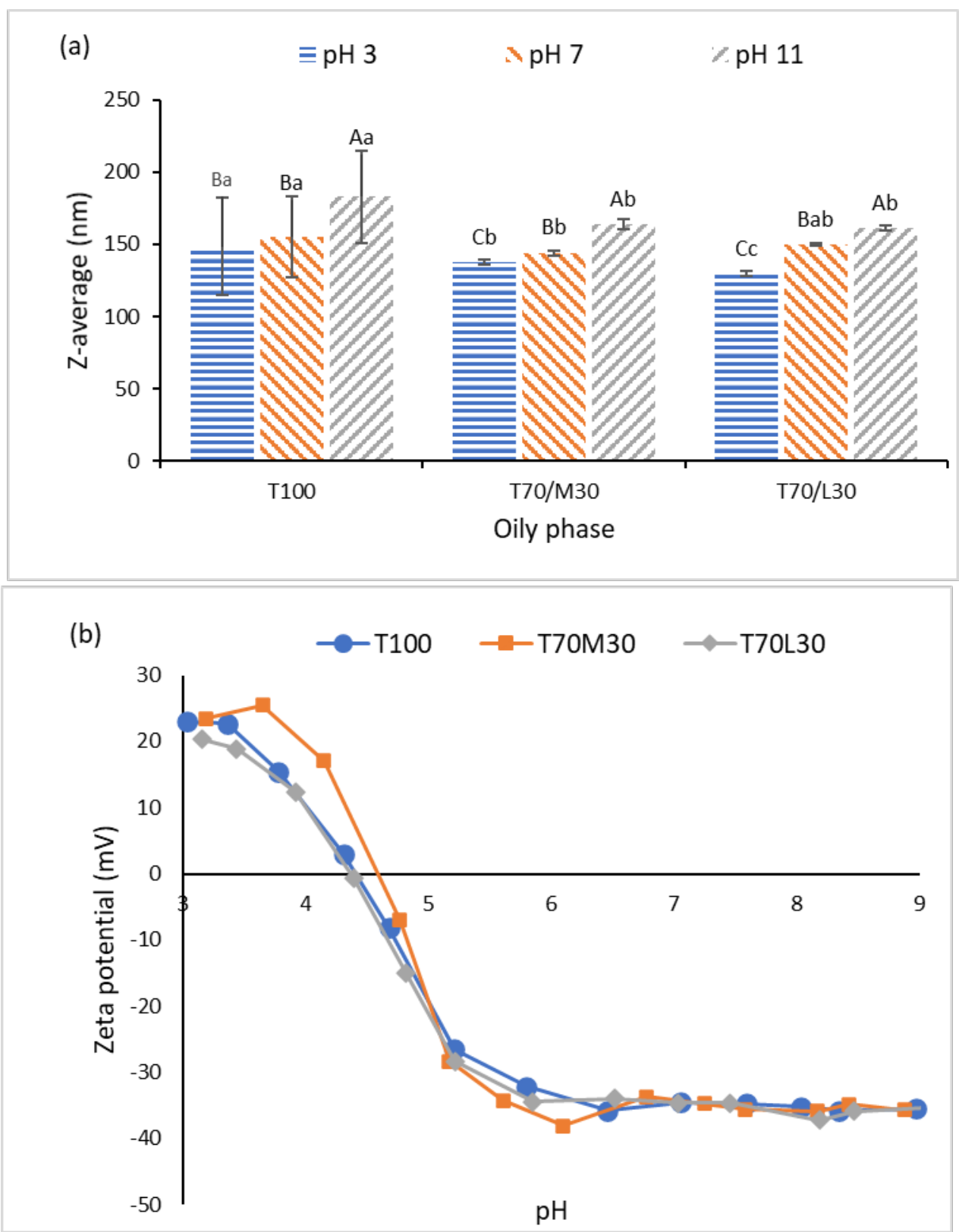

Fig. 5. Effect of $\mathrm{pH}$ on particle size (a) and $\zeta$-potential (b) of caseinate-stabilized nanoemulsions

538 containing different oily phases. The italic number above each bar refers to the PdI value. Samples with 539 different uppercase superscripts $(\mathrm{A}-\mathrm{C})$ differ significantly $(p<0.05)$ when the same nanoemulsion is 540 compared at different $\mathrm{pHs}$; Samples with different lowercase superscripts (a-c) differ significantly $(p<$ 


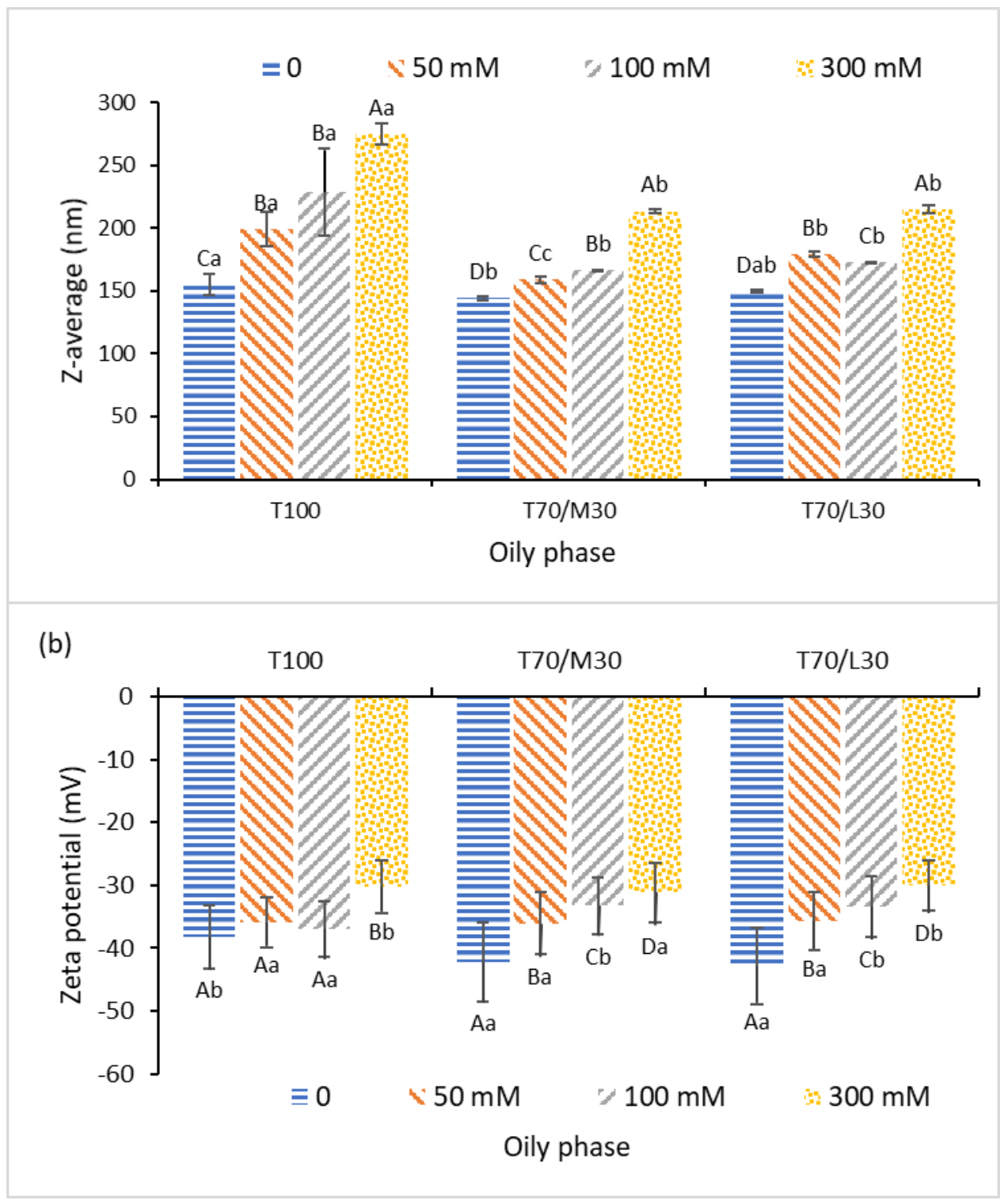

$543 \quad$ Fig. 6. The effect of salt concentration on particle size (a) and $\zeta$-potential (b) of caseinate-stabilized 544 nanoemulsions containing different oily phases. The italic number above each bar refers to the PdI value. 545 Samples with different uppercase superscripts (A-D) differ significantly $(p<0.05)$ when the same 546 nanoemulsion is compared at different salt concentrations; Samples with different lowercase superscripts $547 \quad(\mathrm{a}-\mathrm{c})$ differ significantly $(p<0.05)$ when the different nanoemulsions are compared at same salt concentration. 


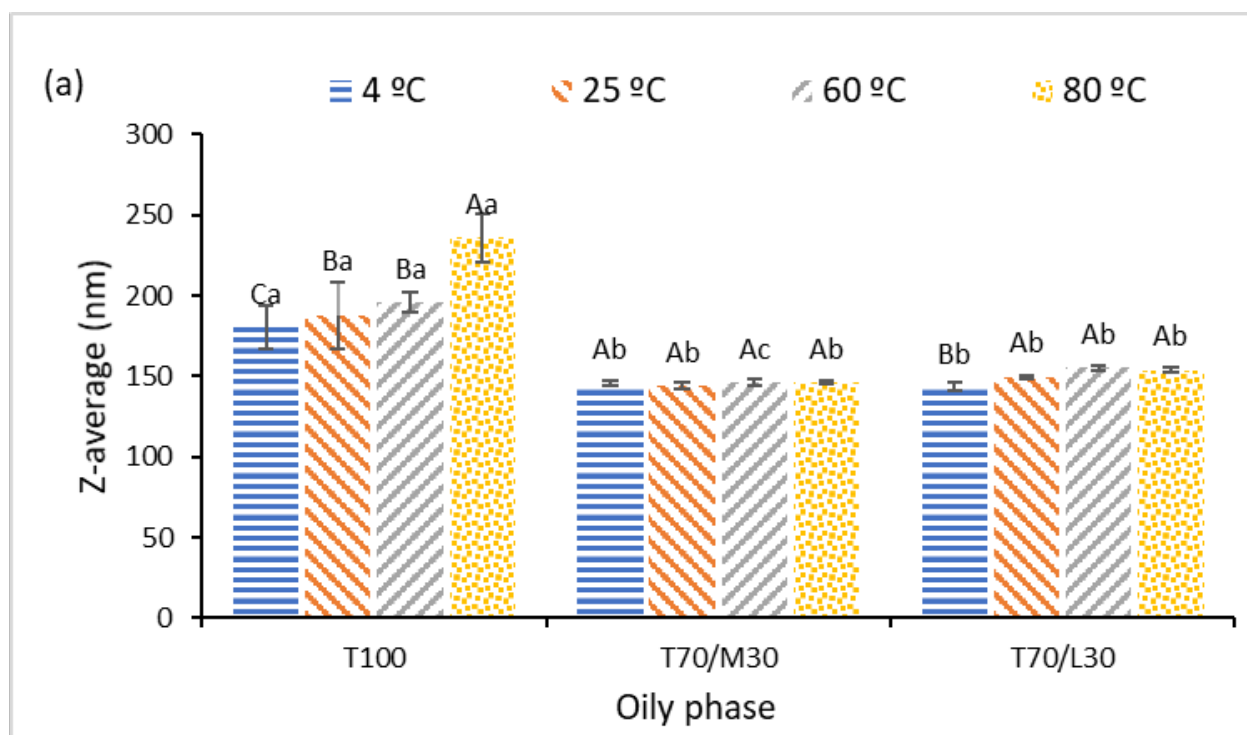

Fig. 7. The effect of temperature on particle size (a) and $\zeta$-potential (b) of caseinate-stabilized nanoemulsions containing different oily phases. The italic number above each bar refers to the PdI value.

552 Samples with different uppercase superscripts (A-D) differ significantly $(p<0.05)$ when the same 553 nanoemulsion is compared at different temperatures; Samples with different lowercase superscripts (a-c) 554 differ significantly $(p<0.05)$ when the different nanoemulsions are compared at same temperature. 


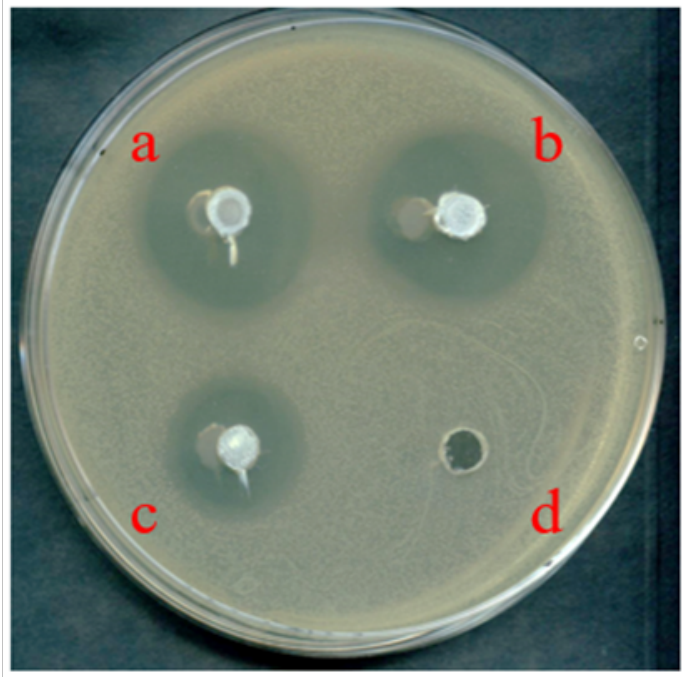

Escherichia coli

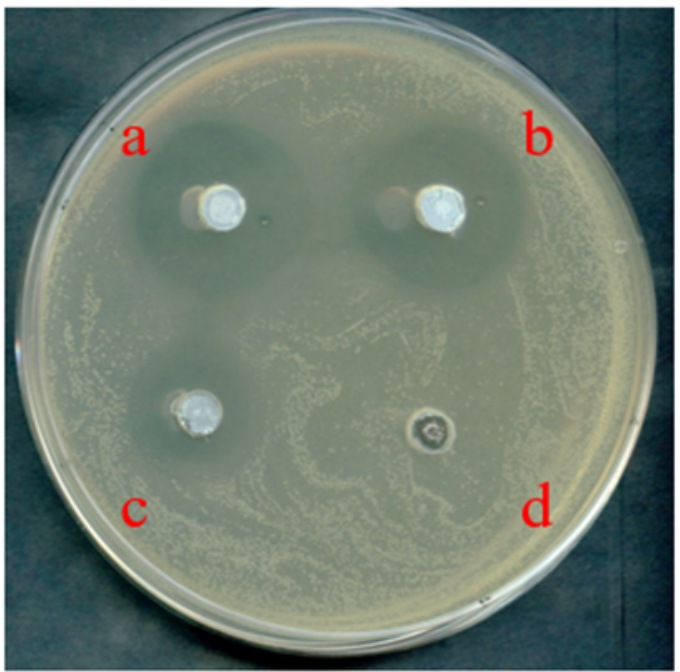

Listeria innocua

$$
=\mathrm{T} 100 \quad \mathrm{TT} 7 \mathrm{~T} / \mathrm{M} 30 / \mathrm{L} 30
$$

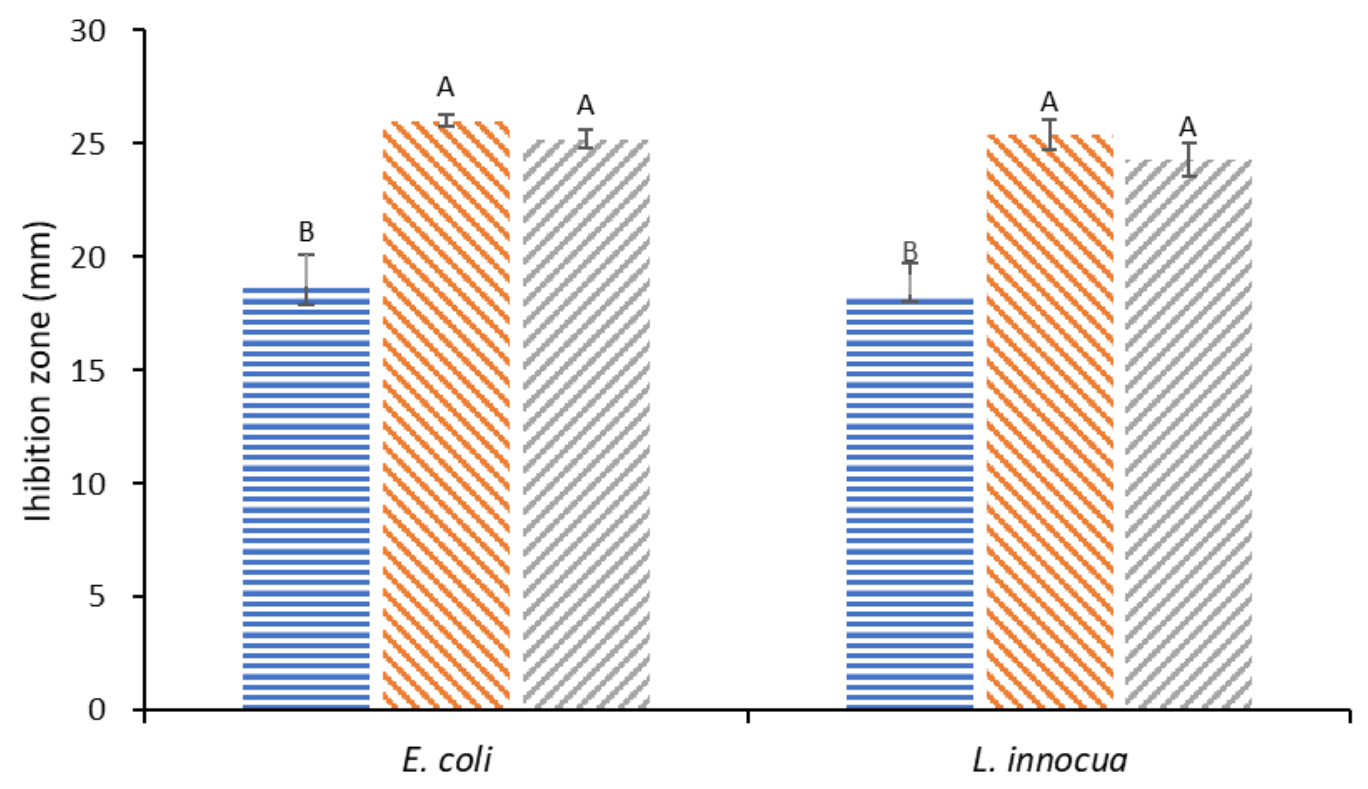

Fig. 8. Top : Example of inhibition zones on TSA containing Escherichia coli and Listeria innocua with four nanoemulsions: T100 (a), T70M30 (b), T70L30 (c) and M100 (d). Bottom : Measured diameter of

558 inhibition zone of three nanoemulsions against Escherichia coli and Listeria innocua: T100, T70M30 and 559 T70L30. Samples with different uppercase superscripts (A-C) differ significantly $(p<0.05)$. 